ESCRITAS Vol. 9 n. 1 (2017) ISSN 2238-7188 p. 202-221

\title{
PAISAGENS IDEOLÓGICAS: MONUMENTOS E EDIFICAÇÕES CATÓLICAS EM ARAGUAÍNA-TO
}

\section{IDEOLOGICAL LANDSCAPES: MONUMENTS AND CATHOLIC BUILDINGS IN ARAGUAÍNA - TO}

\author{
Plábio Marcos Martins Desidério* \\ Marcelo Trilha Muniz** \\ Súsie Fernandes Santos Silva***
}

\begin{abstract}
RESUMO: Este artigo procura discutir, a partir da geografia cultural, os conceitos de paisagem e ideologia e com os mesmos se relacionam, para compreender o termo paisagem ideológica e seus desdobramentos. Para subsidiar a discussão utilizaremos como objeto empírico, monumentos e edificações na cidade de Araguaína-TO, pois podem ser percebidos como exemplos, de paisagens simbólicas e que contribuem para a presença da religião no município. A metodologia utilizada consiste no levantamento do material bibliográfico, em visitas a monumentos e edificações que representam a paisagem ideológica católica, bem como entrevistas com pessoas possuem informações sobre as construções das edificações numa perspectiva hermenêutica. Buscou-se nesta pesquisa mostrar que a paisagem do catolicismo está presente em edificações e monumentos do município, produzindo uma paisagem ideológica com sentido religioso.

PALAVRAS-CHAVE: Paisagem, ideologia; representações; catolicismo; AraguaínaTO.
\end{abstract}

\begin{abstract}
This article seeks to discuss, from the cultural geography, the concepts of landscape and ideology and with themselves relate, to understand the term ideological landscape and its unfolding. In order to subsidize the discussion, we will use as empirical objects, monuments and buildings in Araguaína-TO city, as they can be perceived as examples, of symbolic landscapes and that contribute to the presence of religion in the municipality. The methodology used is the collection of bibliographical material, visits to monuments and buildings that represent the catholic ideological landscape, as well as interviews with people have information on the construction of buildings in a hermeneutical perspective. In this research sought to show that the landscape of Catholicism is present in buildings and monuments of the municipality, producing an ideological landscape with religious sense.
\end{abstract}

KEYWORDS: Landscape, ideology; representations; catholicism; Araguaína-TO.

\section{Introdução}

$\mathrm{O}$ artigo pretende compreender a relação entre significados religiosos e a questão da paisagem para permitir um olhar sobre as paisagens ideológicas materializadas em edificações católicas no município de Araguaína-TO. 
Utilizando a perspectiva de que paisagens que são recortes de espaços abarcados de significações. Estes fragmentos dotados de sentido do espaço podem ser frutos da intencionalidade ou do acaso. Neste estudo, elaborado principalmente sobre a ótica da geografia cultural, pretende-se proporcionar uma reflexão sobre a compreensão do conceito de paisagens ideológicas e sobre edificações católicas da cidade de Araguaína-TO.

Para o olhar comum do homem e da mulher, no cotidiano, despreocupados com análises acadêmicas ou com profundos exercícios de decodificar o mundo que os cercam, uma paisagem pode representar beleza, repulsa ou indiferença. Essas concepções surgem de acordo com os significados que conferem os pontos específicos dos lugares com que têm contato, bem como de suas experiências no espaço de entorno.

Mesmo que as pessoas não percebam ou reflitam sobre a questão, as paisagens que estão ao seu redor apresentam plenas de significações. Algumas surgem espontaneamente, da relação cultural entre as pessoas e a natureza, e outras podem ser influenciadas e criadas com um propósito específico.

Construções católicas estão presentes na cidade de Araguaína e geralmente são de fácil identificação e conhecidas da maioria dos moradores locais, as quais podem ser apontadas como estruturas artificiais, que contribuem para a construção de uma paisagem ideológica, como abordaremos durante o artigo.

Claval (2007, p. 16 e 17) aponta que identidades compartilhadas de um determinado local, podem ser influenciadas por construções que possui elementos religiosos, como uma igreja, também outros tipos de monumentos e até mesmo com o estilo da arquitetura. Algumas destas marcas, juntamente com a delimitação das fronteiras, determinam a "tomada de posse". No Brasil, por exemplo, como em vários outros países, uma igreja católica e seu edifício é encontrada dispersas pelas cidades, como no centro ou em locais elevados, visíveis para toda a população.

Assim, pode-se entender que a demarcação do poder da religião católica é uma forma de impor a sua territorialidade através de presença, demonstrando que aquele local já foi conquistado e pertence para um determinado grupo. Da mesma forma, outras estruturas construídas, como monumentos, escolas, universidades, hospitais, por exemplo, podem servir ao mesmo objetivo ideológico religioso: demarcar território e promover o catolicismo. 
Este artigo procurou problematizar a seguinte questão: algumas edificações católicas na cidade de Araguaína podem ser compreendidas, a partir do termo paisagens ideológicas?

Em Araguaína, cidade situada ao norte do estado do Tocantins, existe a Paróquia Sagrado Coração de Jesus, demarcando o centro da cidade junto a mais conhecida e frequentada praça pública, a Praça São Luiz Orione, também conhecida como Praça das Nações ou Praça da Matriz. Além desta edificação, podem ser identificadas outras construções que configuram paisagens ideológicas católicas, em pontos diferentes da cidade, como a réplica da estátua do Cristo Redentor, monumento Orionita Nossa Senhora da Rosa Mística e a Paróquia São José Operário e sua escadaria no setor JK.

Construções ligadas à religião católica de Araguaína foram selecionadas e serão apontadas, neste estudo, como paisagens ideológicas da cidade. Não seria possível listar e apontar todas as estruturas católicas, portanto quatro pontos foram selecionados e serão abordados no texto.

A intenção deste artigo também não é realizar uma análise do catolicismo e de sua relação com a sociedade araguainense, mas compreender o conceito de paisagens ideológicas e problematizar a presença das estruturas materiais (edifícios, monumentos) na paisagem da cidade e que podem ter contribuído com a reprodução do poder simbólico religioso na comunidade local.

Pretende-se contextualizar o conceito de paisagem, de acordo com a geografia cultural, discutir a construção de estruturas artificiais humanas que podem configurar-se em paisagens ideológicas e apontar exemplos de paisagens ideológicas católicas em Araguaína. Para isso teremos uma perspectiva fenomenológica, a partir de uma dimensão hermenêutica de análise.

\section{Paisagem}

O conceito de paisagem é antigo e evoluiu juntamente com os avanços da sociedade humana e dos estudos ao seu respeito, principalmente no campo da geografia cultural, a partir dos anos 50. A noção de paisagem é bastante difundida e amplamente reconhecida pelo senso comum, pois, conforme Maximiano (2004, p.84) "está presente na memória do ser humano antes mesmo da elaboração do conceito". 
$\mathrm{O}$ ambiente que cerca os seres humanos podem causar-lhes diferentes sensações, ser envolvido pelos mais variados sentidos, inspirar as mais diversas formas e pode também ser alvo de interpretações.

\begin{abstract}
A paisagem pode ser interpretada como a combinação dinâmica de elementos naturais e antrópicos, inter-relacionados e interdependentes, que em determinado tempo, espaço e momento social formam um conjunto único e indissociável, em equilíbrio ou não, produzindo sensações estéticas como um ecossistema (HARDT, 2000, p.15).
\end{abstract}

É evidente que uma pessoa que mora num determinado local e que desenvolveu determinadas significações, para uma paisagem, pode ver e sentir de forma diferente de um visitante ou de alguém que contempla um certo cenário pela primeira vez. Pode mesmo ter diferentes percepções de outras pessoas de sua comunidade, pois uma paisagem não confere um sentimento determinado, mas decorre da relação entre seres humanos com um ambiente com o qual têm contato. Forma-se uma tessitura histórica e cultural carregada de sentido.

Conforme Simmel (2009, p. 06 e 07), ocorre um "acto espiritual” “[...] não há como acorrentar o nosso espírito" e nem sempre o indivíduo está consciente do fenômeno.

\footnotetext{
Mas, para a paisagem é justamente essencial a demarcação, o ser-abarcada num horizonte momentâneo ou duradouro; a sua base material ou os seus fragmentos singulares podem, sem mais, surgir como natureza - mas, apresentada como "paisagem", exige um ser-para-si talvez óptico, talvez estético, talvez impressionista, um esquivar-se singular e característico a essa unidade impartível da natureza, em que cada porção só pode ser um ponto de passagem para as forças totais da existência.
}

A paisagem pode surgir de um determinado lugar que se goste de ficar, num olhar que admira um belo jardim, um lago, uma imagem que representa a fé ou algo importante ou a imponência de uma grande obra da engenharia humana. Pode, também, ser inerente de um ambiente de medo, um local marcado por uma grande tragédia que abala determinadas pessoas, pelas lembranças, pelas histórias contadas, pelos mitos ou ganha esta percepção pelo perigo que um espaço pode proporcionar, como uma área violenta de uma cidade ou um ambiente naturalmente inseguro.

É um recorte da natureza com seu significado, que se destaca na percepção humana. Surge um elo sentimental diferenciado, criado através de um processo de 
interação cultural das pessoas com este fragmento do mundo, que seus olhos e sua mente capturaram e deram sentido a esse espaço.

Para Gomes (2001, p. 56 e 57), a paisagem é denotada pela morfologia e contada pelo conteúdo e processo de captura e representação. Esclarece que a paisagem como representação resulta da apreensão do olhar do indivíduo que, por sua vez, é condicionado por filtros fisiológicos, psicológicos, socioculturais e econômicos, e da esfera da rememoração e da lembrança recorrente. Ela só existe a partir do indivíduo que a organiza, combina e promove arranjos do conteúdo e forma dos elementos e processos, num jogo de mosaicos, de pedaços de mundo.

A paisagem evoca significados a partir dos signos e valores atribuídos. Esses signos assumem amplo espectro de propriedades e escalas numa grade semântica própria. Dessa forma, a paisagem pode ser observada como objetivo real, passível de análise, relacionado ao cientificismo; como um fenômeno do mundo a nossa volta; como espaço físico percebido; como relação das sociedades com a natureza.

Olhar, ouvir, saborear, cheirar, tocar. Os sentidos humanos, os processos de interação, as experiências vivenciadas num local interferem nesse processo de significação. Santos (2008, p. 40) explica o termo paisagem da seguinte forma:

Tudo aquilo que nós vemos, o que nossa visão alcança. [...] A paisagem é um conjunto de formas heterogêneas, de idades diferentes, pedaços de tempos históricos representativos das diversas maneiras de produzir as coisas, de construir o espaço. Esta pode ser definida como o domínio do visível, aquilo que a vista abarca. Não é formada apenas de volumes, mas também de cores, movimentos, odores, sons etc. (SANTOS, 2008, p. 40)

Schama (1996, p. 70), em sua obra que entrecruza geografia, história e arte para refletir a paisagem e afirma que "paisagem é cultura antes de ser natureza", apontando que o meio ambiente é impregnado de sentido, carrega traços de memória e pode ser percebido, descrito, lido, inspirando as mais diversas construções simbólicas humanas.

\section{Ideologia}

A ideologia pode refletir autoritarismo, radicalismo, esperança e causar revoluções ou acomodação com a ordem vigente. É uma poderosa força que atravessa grupos humanos, os preenche de significações, mobiliza suas vidas, dando sentido as suas existências. 
Para Chaú (2014, p. 117) a ideologia é percebida na sistematização das ideias, regras de conduta e valores dos grupos sociais. São "representações com teor explicativo" que constroem a realidade dos sujeitos. Neste sentido, vivenciar a representação de ser de uma determinada nacionalidade, sentir-se pertencendo a um território e acreditar que se está inserido numa unidade cultural com preferências comuns aos demais cidadãos, com "amigos da nação e inimigos a combater", são elementos que compõe esta sistematização.

Ainda argumenta Chauí (2014, p.149), que esses fatores são construídos historicamente e socialmente pelas próprias pessoas em suas interações, mas também pela atuação do estado (sistema escolar, por exemplo), pela mídia, pelas religiões e por todas as demais forças, em conflito ou não, do território em que se está inserido.

Os grupos dominantes, conscientemente ou não dos efeitos de sua atuação social, criam estruturas que edificam sua posição de poder.

\begin{abstract}
"O conceito de "ideologia" reflete uma das descobertas emergentes do conflito político, que é a de que os grupos dominantes podem, em seu pensar, tornar-se tão intensamente ligados por interesses a uma situação que simplesmente não são mais capazes de ver certos fatos que iriam solapar seu senso de dominação. Está implícita na palavra "ideologia" a noção de que, em certas situações, o inconsciente coletivo de certos grupos obscurece a condição real da sociedade, tanto para si como para os demais, estabilizandoa portanto. (MANNHEIM, 1976, p. 66-67).
\end{abstract}

No entanto, não é possível afirmar que toda a ideologia mascara/obscurece uma "realidade". Ela apresenta-se como forma de significar e orientar o comportamento dos grupos sociais, manifestações coletivas que contribuem com a quebra de paradigmas perversos e lutas de minorias pelos seus direitos, como movimentos feministas, LGBTT (Movimento que integra Lésbicas, Gays, Bissexuais, Transgêneros e Transexuais) e étnicos raciais, por exemplo, representam ideologias progressistas que combatem desigualdades estabelecidas na sociedade.

Para ir além da tradição marxista de ideologia recorremos a perspectiva de Mannheim, analisada por Thompson (2011). Para Mannheim a ideologia deve ser percebida também como uma dimensão cognitiva, por isso que ele a insere na sociologia do conhecimento. Conforme Thompson aponta:

[...] O interesse principal de Mannheim é ir além do caráter partidário das primeiras teorias e transformas a análise da ideologia numa sociologia do conhecimento, que estaria baseada na formulação geral da concepção total de ideologia. "Ideologia", dentro desse novo programa, refere-se, essencialmente, a um sistema de pensamento e ideias que são situados socialmente e coletivamente compartilhados; e a análise ideológica é o estudo 
das maneiras como esses sistema de pensamento e ideais estão influenciados pelas circunstâncias sociais e históricas em que estão situados [...] (THOMPSON, 2011, p. 69).

A ideologia segundo Mannheim - nos apontamentos de Thompson - difere da utopia (essa com dimensão de mudança) e não se restringe às relações de dominação, perspectiva bastante presente na tradição marxista. Nesse sentido pode-se entender a ideologia em muitas perspectivas e que inclusive está inserida na relação de forças entre e grupos e instituições e que estão em disputa. Essa relação de força (poder) pode ser compreendida, a partir dos apontamentos de Foucault (2000).

Foucault (2000, p.VII-XXIII) nas observações de Roberto Machado, considera que o poder atua como uma complexa rede, disseminada por toda a estrutura da sociedade. Funciona através de campos formados por pares de interesse, com suas regras próprias que influenciam e buscam orientar a convivência coletiva em seu benefício. São forças distintas de grupos de pessoas, ajustando-se numa constante competição estratégica e em diferentes níveis. Para esse autor, não há uma posse do poder, mas sim um constante exercício.

Estas lutas assentam as ideologias e a convivência social, portanto não se pode afirmar que o desejo das forças soberanas seja imposto e determinante sobre todos. Não é um processo fechado em que os grupos dominantes simplesmente impõem suas dominações, mas sim dinâmico, um constante jogo de negociações de interesses. Pessoas podem ser influenciadas, mas podem aceitar ou não, ou ainda aceitar apenas parte do que lhes é imposto, de acordo com cada contexto.

Ricoeur (1990, p. 68 e 69) destaca o pensamento de Jacques Ellul (1973, p. 335-354), que aponta que a ideologia não apenas propaga, mas também justifica o seu conjunto de signos, proporciona condições do grupo defender a razão de ser o que é, justamente pelo fator de que "toda a ideologia é simplificadora e esquemática".

Ainda argumenta que o código ideológico é fundamental para a tomada de consciência de um indivíduo inserido em determinado grupo comportamental. (RICOEUR, 1990, p. 71).

Em sua reflexão, esse autor afirma que pela estruturação e força que exerce sobre as sociedades humanas, a religião, neste contexto, é uma "ideologia por excelência", uma representação máxima da sistematização de ideias que dá sentido ao mundo dos grupos de indivíduos. (RICOUER, 1990 p.68-73). 


\section{Paisagens ideológicas e edificações católicas de Araguaína}

Como um recorte da natureza pode ser carregado de sentido, a paisagem pode ser preenchida ideologicamente, compondo um mosaico de sensações e lembranças que constroem a percepção da realidade dos sujeitos.

A sociedade humana explorou e explora o mundo ao seu redor, o espaço que utiliza para sobreviver e criar seus códigos de orientação, de posse e seus sistemas de representação cultural nestes ambientes.

Para Claval (2007, p. 189) “As relações do indivíduo com o espaço fazem parte dos primeiros aprendizados culturais e não cessam de se desenvolver”. Portanto, é um processo contínuo e dinâmico, decorrente da relação do sujeito com o ambiente que o cerca, um processo que produz cultura. “[...] cultura é o sistema significante através do qual [...] uma ordem social é comunicada, reproduzida, experimentada e explorada". (MELO. 2001, p. 37).

Para Luchiari (2001 p. 12), levando-se em consideração que a produção humana altera a paisagem, não se deve analisar a paisagem sem considerar as práticas sociais dos homens e mulheres. "[...] o domínio ideológico que estrutura o espaço total está representado também na organização social das paisagens". A paisagem pode ser "a própria representação do espaço social".

A cultura dominante pode influenciar o surgimento de paisagens de acordo com sua imagem de mundo, com seus interesses e, muitas vezes, conseguir que essas imagens e representações sejam aceitas como a realidade representada de todos. No entanto, também surgem paisagens alternativas, produzidas por grupos não-dominantes e geralmente com menor visibilidade. (MELO, 2001, p. 40).

[...] de acordo com Duncan (1990, p. 18), as paisagens não serviriam apenas para atender as necessidades funcionais dos homens, nem representariam simplesmente criações culturais localizadas, pois as formas que tomam através dos conjuntos arquitetônicos traduzidos por signos, símbolos e ícones representam a história que grupos - principalmente os grupos poderosos contam sobre eles mesmos. (MELO, 2001, p. 44)

A forma que a sociedade se organiza e cria suas culturas gira em torno dos seus modelos de produção. A atuação humana interferiu em praticamente todo $\mathrm{o}$ território planetário, impulsionada por “[...] intenções econômicas ou políticas”. Foram as necessidades e os interesses que moveram pessoas e formaram as sociedades, suas territorializações, desterritorializações e novas reterritorializações. 
Santos (2008, p. 40) aponta que praticamente "não existem mais paisagens naturais", ambientes que não sofreram alterações da ação humana.

Melo (2001, p. 37) concorda com o argumento de Santos (2008), de que o trabalho e a produção humana são os fatores que significam o mundo, criam cultura, através das relações sociais e de poder. A autora recorre a Duncan (1990, p. 05), ao citar Denis Cosgrove, que baseou seu conceito no pensamento de Raymond Williams para reforçar o seu argumento: "[...] a paisagem deve ser analisada como resultante da forma como a sociedade a organiza a partir do modo de produção, dotando-a de significado".

Quem controla os meios de produção, detém o capital, possui forte influência na mídia, acaba tendo melhores condições de formar opiniões, influenciar culturas no jogo de ajustes entre todas as forças locais e, pode até mesmo criar hegemonias culturais, reterritorializando ao seu favor. Dessa forma, "Um grupo dominante procurará impor sua própria experiência do mundo". (COSGROVE, 1998, 104).

Para Tuan (2013 p. 211): “A cidade é um lugar, um centro de significados, por excelência. Possui muitos símbolos bem visíveis”. São marcas que orientam, as vidas das pessoas, que fazem com que os indivíduos sintam que pertencem a um determinado espaço que lhes é familiar. Forma-se uma conexão emocional, afetiva e histórica através das vivências no lugar.

Esta conexão pode ser influenciada por grupos de pessoas, através de discursos e símbolos criados para demarcar posições de poder ou influenciar o comportamento dos membros de uma determinada sociedade. Uma ideologia pode ser estimulada, não determinada, mas influenciada pela atuação de representantes de um determinado interesse.

Figura 1 - Cristo Redentor - Rio de Janeiro-RJ.

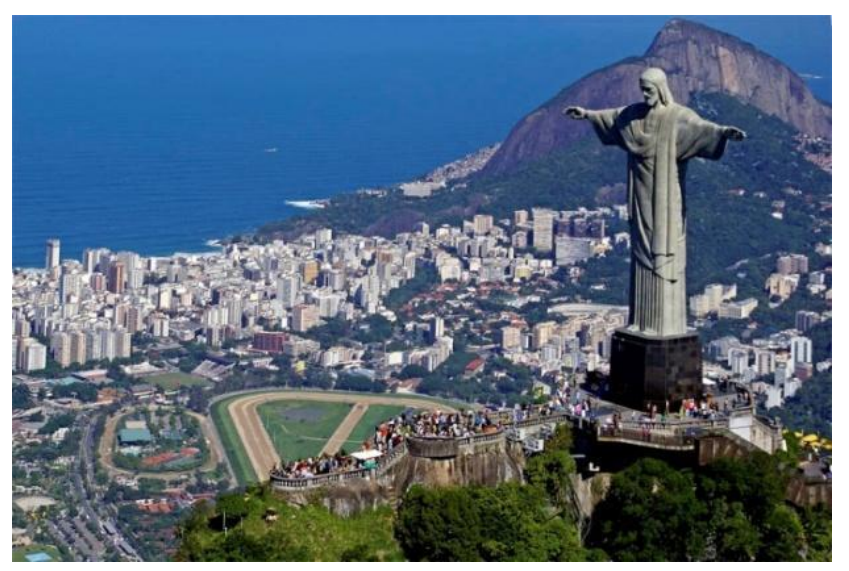


Fonte: Angular Fotos Aéreas (João Luiz dos Anjos) ${ }^{1}$

A estátua do Cristo Redentor no Rio de Janeiro é mundialmente conhecida. Uma grandiosa obra da arquitetura humana. Construída num lugar paradisíaco, nas alturas, como se tocasse o céu e tornou-se um dos principais atrativos turísticos da cidade.

A proposta da construção surgiu em 1859, através do padre Lazarista Pedro Maria Boss, que desejava homenagear a princesa Izabel, regente do Brasil. Mas como em 1889 o país tornou-se uma república e foi oficializada a separação entre Igreja e Estado, o projeto foi descartado.

Conforme informações disponíveis no portal Cristo Redentor 80 anos, em 1921, após uma assembleia do circuito católico do Rio de Janeiro, com o tema "Semana do Monumento", a proposta foi retomada, como forma de comemorar o centenário da independência do país.

Após campanha nacional de arrecadação de fundos, da escolha do Cristo de braços abertos, representando a paz, a estátua projetada pelo engenheiro Heitor da Silva Costa e esculpida pelo artista franco polonês Paul Landowski, foi inaugurada em 1931.

O Cristo Redentor é nitidamente um símbolo do catolicismo nacional. Demonstra poder pela sua magnitude e contribui com a continuidade e o fortalecimento de determinadas ideias de grupos ideológicos que compõe o país.

Figura 2 - Templo de Salomão - São Paulo-SP.

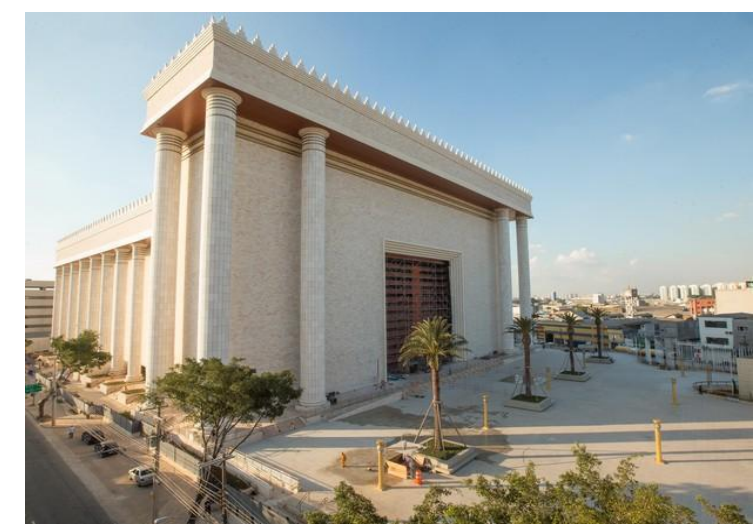

Fonte: G1 Globo - São Paulo²

\footnotetext{
${ }^{1}$ Disponível em:

2 Disponível em:

<https://www.google.com.br/search?q=templo+de+salom\%C3\%A3o\&biw=1370\&bih=639\&source=Inms
} 
Conforme informações do Portal G1 Globo - São Paulo, o Templo de Salomão, inaugurado em 2014, na cidade de São Paulo, pela Igreja Universal (evangélica neopentecostal), possui 74 mil metros quadrados de área construída e capacidade para receber mais de 10.000 pessoas nos cultos. Atualmente é o maior espaço religioso do Brasil.

Pela imponência e simbologia da obra, cria novas paisagens ideológicas e edifica ainda mais a força das pessoas e da religião que o construíram no país. O local, inclusive, pode ser apontado como um marco do grande crescimento, nos últimos anos, das religiões evangélicas no Brasil.

Observando estas duas grandes obras da arquitetura religiosa brasileira e suas simbologias, pode-se assegurar que uma paisagem não surge apenas da relação natural entre pessoas com determinadas recortes de lugares, mas que pode ser influenciada com uma nítida intenção ideológica.

Uma tradição é marcada pela característica da "invariabilidade", determinando o funcionamento e as relações sociais de grupos de pessoas num determinado espaço. Pode ser inventada e institucionalizada através da repetição de "práticas rituais ou simbólicas" que definem os valores e as normas de convívio coletivo. Fatores que norteiam as vidas das pessoas inseridas num determinado espaço e contexto. (HOBSBAWN e RANGER, 1997, p. 9, 10 e 12)

Tradições foram inventadas ao longo da história para manter ou alterar a organização social de comunidades ou nações. A ideologia de um grupo dominante é o elo norteador da criação de uma tradição. Interfere-se numa situação de acordo com os sistemas de ideia dos que coordenam as ações que pretendem orientar os rumos de uma sociedade.

As alterações humanas do ambiente, interferindo na natureza, construindo obras carregadas de simbologias e que podem tornar paisagens ideológicas, são formas de difundir determinadas ideologias e de fortalecer determinados poderes que atuam sobre aquele grupo de pessoas. Para compreender essa relação entre paisagem e ideologia e atender o objetivo do artigo iremos elencar e problematizar

Araguaína é uma das maiores cidades do Tocantins. Situada ao norte do estado, próxima aos estados do Pará e do Maranhão, na região norte do Brasil. De 
acordo com informações do Instituto Brasileiro de Geografia e Estatística (IBGE), através do censo de 2010, o município possuía 150.484 habitantes e a estimativa é de que em 2015 tinha 170.083 pessoas, morando na cidade.

É uma cidade jovem, somente em 1958 tornou-se município, período em que começou a crescer mais rapidamente por estar situada às margens da rodovia Belém-Brasília (BR-153), que foi construída entre os anos 50 e início dos 60.

A separação do Tocantins do estado do Goiás contribuiu ainda mais com o crescimento da cidade. Atualmente, conforme informações disponíveis no portal da Associação Comercial e Industrial de Araguaína (ACIARA), a economia é baseada principalmente na pecuária (criação de gado), comércio, saúde (pólo regional) e educação (possui estruturada rede pública e privada de ensino básico e médio, no ensino superior o município é contemplado com uma instituição de ensino federal e três particulares presenciais). Araguaína também conta com polos de educação a distância de instituições privadas e um polo de instituição pública.

A Igreja Católica, instituição cristã com aproximadamente dois mil anos de história é a instituição religiosa com maior número de seguidores. Suas missas são realizadas todas as semanas, suas tradições guiam a vida de muitas pessoas e seus símbolos estão espalhados por praticamente todo o globo, demarcando sua posição de poder.

No Brasil, de acordo com o Censo de 2010, publicado pelo Instituto Brasileiro de Geografia e Estatística (IBGE), 64,6\% da população era católica, 22,2\% era evangélica, $2 \%$ era espírita, $0,3 \%$ era umbandistas e candomblecistas e $8 \%$ não declararam religião. Em Araguaína-TO, de acordo com o mesmo censo, existiam 72,4\% de católicos, 26,8\% evangélicos e $0,8 \%$ de espíritas.

Estes números confirmam a dimensão da religião católica no Brasil e em Araguaína, mesmo com o recente crescimento evangélico, principalmente na última década, são dados muito fortes e que foram histórica e culturalmente construídos.

Para Claval (1999, p. 51) tanto a religião quanto uma ideologia conseguem responder questionamentos humanos com relação ao sentido de sua existência. Fazem com que se sintam integrados a um grupo de pessoas, a um propósito. Mesmo que muitas vezes ajam irracionalmente, este conjunto de signos imateriais pode amenizar conflitos e dúvidas dos pensamentos dos habitantes de determinado lugar.

Muitos significados podem estar contidos numa paisagem. A religião certamente é um deles. E como estruturas podem ser criadas com a intenção de 
demonstração ou fortalecimento de poder, paisagens ideológicas católicas surgiram demarcando territórios e orientando a cultura de seus habitantes.

Embora lugares sagrados possam resultar de processos de sacralização, as paisagens são criadas por determinados grupos religiosos, no desejo de reproduzir sua própria visão de mundo. Bonnemaison (1981) nos leva a reconhecer que os símbolos ganham mais força e realce quando se encarnam em lugares religiosos. O espaço é percebido como uma trama geossimbólica de comunicação partilhada por todos. A paisagem é uma estrutura visível, na qual a mensagem que nela se escreve em termos geossimbólicos reflete no peso do sonho, das crenças dos homens e de sua busca de significação. (ROSENDAHL 2007 p. 214).

Araguaína possui muitos símbolos do cristianismo que podem ser facilmente identificados. Locais públicos com crucifixos, imagens de Nossa Senhora Aparecida fixadas nos muros das residências, adesivos nos veículos e até mesmo placas de trânsito em rotas que levam a cidade com mensagens de cunho religioso como "Leia a Bíblia".

Dentre as edificações ligadas a igreja católica, quatro foram selecionadas para serem apontadas neste estudo como paisagens ideológicas da cidade. Para termos uma percepção da distribuição essas edificações na cidade de Araguaína inserimos um mapa para ilustrar a ocupação na cidade:

Figura 3 - Mapa de Araguaína - Distribuição das edificações católicas.

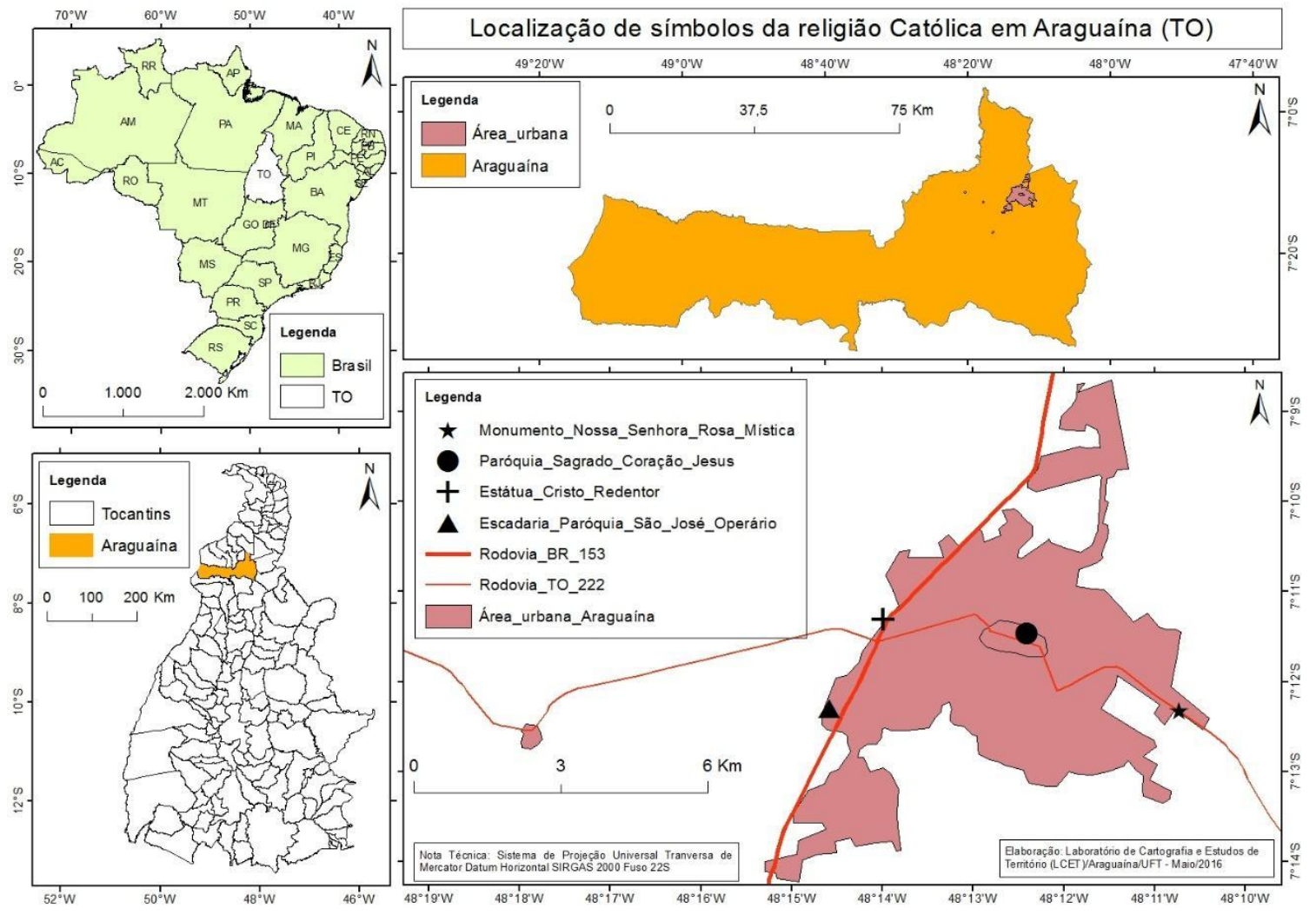


Figura 4 - Paróquia Sagrado Coração de Jesus - Araguaína-TO.

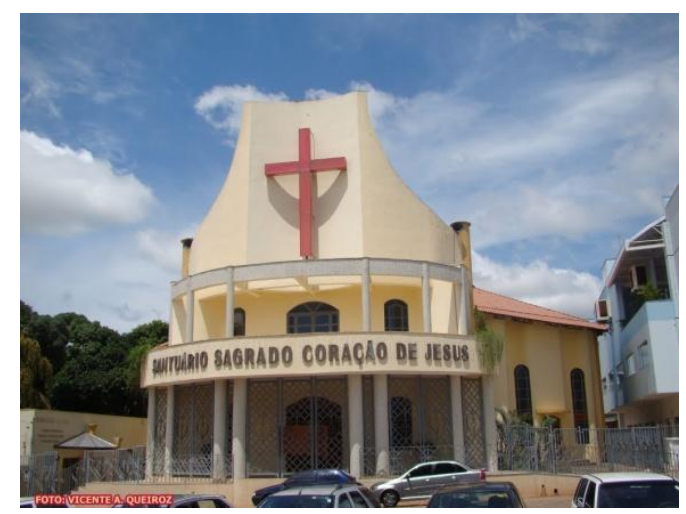

Fonte: www.panoramio.com - Foto de Vicente A. Queiroz ${ }^{3}$

A Paróquia Sagrado Coração de Jesus, também conhecida como Igreja matriz, está situada em área privilegiada. No centro da cidade, junto à principal praça do município, a Praça São Luiz Orione.

A estrutura é imponente, situada na área de maior movimentação populacional de Araguaína, próxima a prefeitura, agências bancárias e da principal rua comercial, demarcando a fé cristã como algo fundamental, incrustado no coração da cidade.

É importante destacar que, além da Paróquia Sagrado Coração de Jesus, outras grandes obras na cidade, católicas e ligadas à ordem orionita ${ }^{4}$, também compõem marcantes paisagens locais, como a Faculdade Católica Dom Orione, o Hospital e Maternidade Dom Orione, o Colégio Santa Cruz, a Casa Tra Noi (albergue), a Creche Mãe de Deus das pequenas Irmãs Missionárias e a escola de ensino fundamental Sagrado Coração de Jesus.

Em 07 de maio de 1957, foi instalada em Araguaína a Paróquia Sagrado Coração de Jesus e iniciou a construção da Igreja Matriz, coordenada pelos orionitas e

\footnotetext{
${ }^{3}$ Disponível em:<http://www.panoramio.com/user/333232/tags/Igrejas\%20-\%20Tocantins>. Acesso em: 03 de dez. 2015

${ }^{4}$ Após ser nomeado sacerdote em 1895, Luiz Orione, juntamente com seminaristas e padres, formaram um núcleo denominado "Pequena Obra da Divina Providência" na Itália. Muitas atividades e projetos foram desenvolvidos por esta congregação, com a intenção de realizar obras de caridades e atrair fieis de baixa renda para a igreja.

Com o passar dos anos e com um legado de inúmeros trabalhos relevantes realizados, dentro e fora da Itália, em 1913, os primeiros missionários orionitas chegaram ao Brasil. Em 1952, quando o Tocantins ainda pertencia ao Goiás, esta congregação chegou ao estado.

Araguaína, neste período, possuía apenas uma cabana de madeira coberta de palha, era uma capela que pertencia a Paróquia Nossa Senhora do Perpétuo Socorro da cidade de Filadélfia. Disponível $\mathrm{em}:<$ http://www.orionitas.com.br/destaques_orionitas_araguana.php $>$. Acesso em: 03 de dez. 2015
} 
contando com auxílio da comunidade. Entre 2006 e 2009 foi realizada a última ampliação e reforma da estrutura que passou por muitas mudanças nos seus mais de 50 anos de história. Da primeira construção em alvenaria, algumas largas paredes de pedra são mantidas até hoje nas laterais da entrada e parte do fundo do presbitério.

As considerações de Polignac (1984, p.30) subsidiou Claval (1999, p. 52) na afirmação que segue sobre a presença do símbolo religioso no espaço:

\section{A aparição do santuário significa uma modificação sensível da percepção do espaço, colocando desde logo um ponto final em seu estado de relativa indeterminação: este espaço é daí em diante organizado, repartido, e fíca nitidamente traçada a fronteira entre sagrado e urbano.}

A congregação orionita foi responsável por conduzir a construção da primeira igreja católica de Araguaína. Participou ativamente com muitos serviços sociais e, certamente, possui uma destacada influência nos elementos que compõem a cultura e as paisagens locais.

Figura 5 - Estátua do Cristo Redentor - Araguaína-TO.

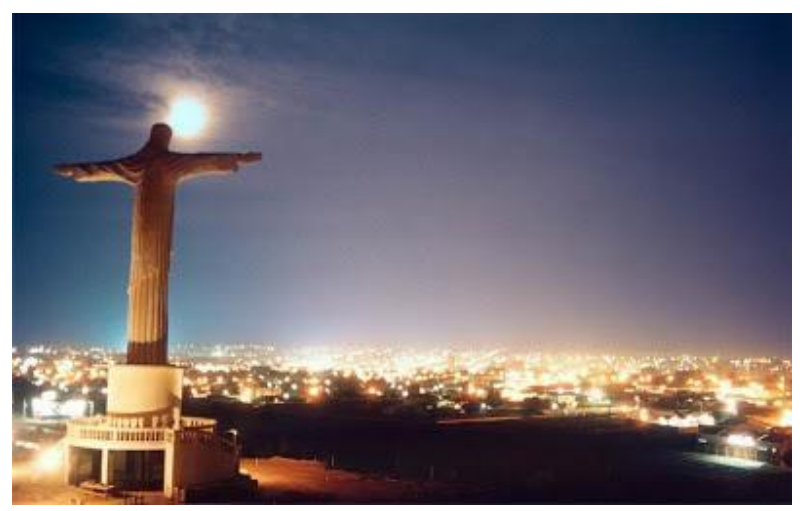

Fonte: www.overmundo.com.br - Foto de Ulisses Holanda ${ }^{5}$

Conforme informações repassadas por Luiz Tupiniquim, coordenador de Cultura da Prefeitura Municipal de Araguaína, respondendo a ofício encaminhado para o departamento, a réplica do Cristo Redentor em Araguaína foi construída com fundos captados junto à iniciativa privada em 2004, durante o mandato da Prefeita Valderez Castelo Branco.

O monumento do Cristo Redentos concebido para ser um dos principais atrativos turísticos de Araguaína, exaltar a fé cristã e como uma tentativa de criar um elemento de identificação visual do município. Está instalado numa área alta, visível de vários pontos da cidade. A estátua fica próxima a BR-153 (Belém-Brasília) e pode ser

\footnotetext{
${ }^{5}$ Disponível em: http://www.overmundo.com.br/guia/bela-araguaina-5. Acesso em: 20 de dez. 2015.
} 
avistada pelos viajantes que trafegam pela principal rota rodoviária que atravessa $o$ município. (TUPINIQUIM, 2016, entrevista).

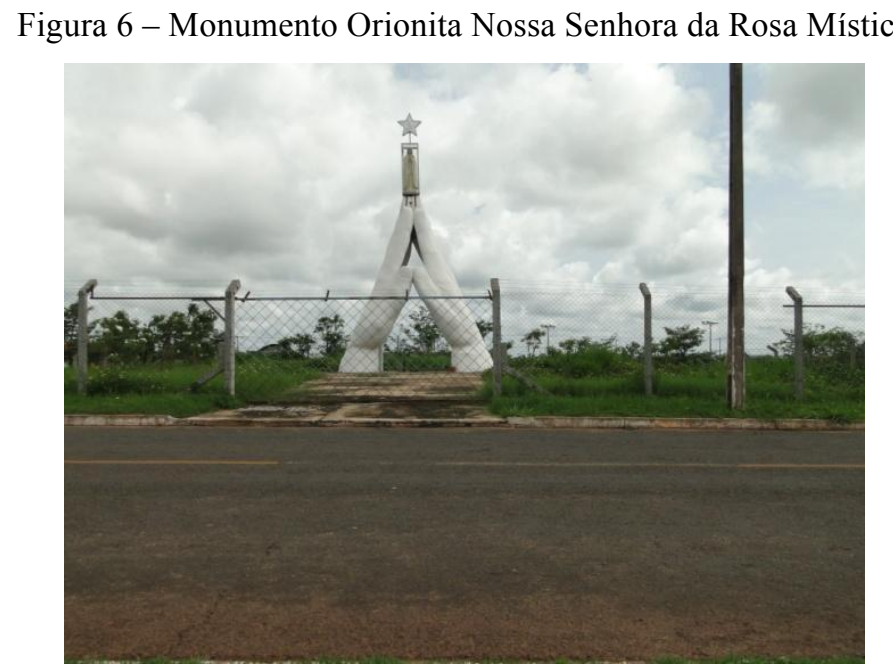

Fonte: fotos da pesquisa $-14 / 01 / 2016$

O Monumento Orionita Nossa Senhora da Rosa Mística ${ }^{6}$ está localizado no Setor Jardim das Flores, às margens da TO 222, a segunda principal rota de acesso a Araguaína. Estrada que liga a cidade ao estado do Maranhão e a cidades como Carolina e Riachão, conhecidas pelos seus atrativos turísticos (cachoeiras e belezas naturais).

Conforme informações repassadas pela secretária da Paróquia Sagrado Coração de Jesus, Maria do Rosário Soares, o monumento foi construído em área própria pela Congregação Orionita para homenagear a Nossa Senhora da Rosa Mística.

Após a conclusão da obra, a imagem da santa foi instalada sob a escultura das mãos e abençoada em 03 de março de 2013, após carreata que iniciou na Paróquia Sagrado Coração de Jesus e percorreu as principais ruas da cidade. (SOARES, 2016, entrevista).

Figura 7 - Paróquia São José Operário e sua escadaria - Araguaína-TO.

\footnotetext{
${ }^{6}$ Nossa Senhora Rosa Mística é um título da Virgem Maria. Trata-se de uma revelação que a própria Virgem Santa fez a uma enfermeira italiana no ano de 1947. Pierina Gilli, a enfermeira, trabalhava no Hospital de Montechiare e estava rezando na Capela quando viu Nossa Senhora. Posteriormente, ela descreveu sua visão e o mundo tomou conhecimento desse novo título de Maria como Nossa Senhora Rosa Mística. Trata-se de uma imagem rica em sua mensagem e simbolismos, expressos através das rosas, das vestes e das cores.

As mãos juntas e o terço de Nossa Senhora Rosa Mística são mais um sinal claro do convite à oração e, especialmente, à oração do terço. Esta oração, como tudo que Nossa Senhora nos pede, é Cristoc6entrica, isto é, tem Jesus no centro. Ao rezar o terço, com efeito, contemplamos os Mistérios da vida de Nosso Senhor Jesus Cristo. Fonte: http:/www.cruzterrasanta.com.br/significado-e-simbolismo-de-nossasenhora-rosa-mistica/289/103/
} 


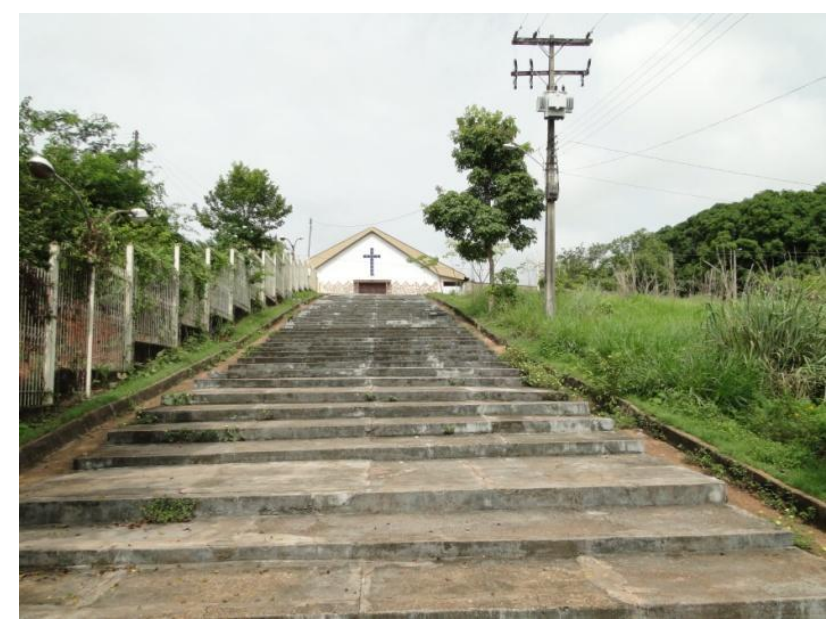

Fonte: foto da pesquisa - 14/01/2016

Outra paisagem urbana católica que pode ser destacada é a Paróquia São José Operário e sua escadaria com mais de 50 degraus, localizada no setor JK. Esta igreja, conforme dados repassados pela secretária da Paróquia, Beatriz Guida Ramos, foi fundada em 16 de junho de 1978 e pertence à Diocese de Tocantinópolis. (RAMOS, 2016, entrevista).

A escadaria e a igreja despertam a atenção de quem passa pelo local. Podem ser visualizadas da BR-153, ao final de uma rua íngreme. Moradores e visitantes de Araguaína frequentam a estrutura, registram fotos no local e algumas pessoas utilizam a escadaria para práticas esportivas.

Araguaína possui muitas marcas do catolicismo que formam paisagens no cotidiano de seus habitantes. São aportes de uma imensa riqueza de representações que merecem ser cada vez mais observados e estudados. Tanto para uma maior compreensão do local, bem como para registrar a peculiaridade da produção cultural humana numa determinada localidade.

\section{CONCLUSÃO}

As quatro construções apresentadas estão situadas em pontos diferentes da cidade, entre muitas outras construções católicas existentes, denotam marcas da religião em Araguaína. Estas edificações e monumentos, sendo o seu propósito ou não, contribuem com a perpetuação e fortalecimento de uma ideologia, configuram-se em paisagens do ambiente e certamente exercem influência na cultura local.

As reflexões deste estudo possibilitaram uma maior compreensão sobre alguns aspectos que definem o araguainense. É evidente que não existe apenas um perfil de morador local, mas existem elementos conhecidos por muitas pessoas na cidade e 
que exercem maior ou menor influência na cultura geral e nas suas formas de perceber o mundo ao seu entorno.

No caso da paisagem religiosa, nota-se claramente que pessoas de outras religiões, ou que afirmam não ter religião, desenvolvem e demonstram sentimentos diferenciados dos adeptos da fé católica diante de seus símbolos. Mas os monumentos e edificações católicos de Araguaína fazem parte da fundação e da história da cidade, estão muito presentes na vida dos moradores locais e, pode-se afirmar, são um dos principais fatores de orientação ideológica de grande parte de seus habitantes.

$\mathrm{O}$ ambiente que cerca as pessoas que vivem numa sociedade pode possuir as mais diversas significações. Umas que surgem ao acaso de suas experiências e outras que podem ter sido influenciadas. "A paisagem urbana é, para além de outras coisas, algo para ser apreciado, lembrado e contemplado". (LYNCH, 1999, p.9). Mas deve-se ir além, deve-se também tentar interpretá-las, buscar compreender o que representa para si e o que significa para as outras pessoas. Este exercício pode possibilitar um maior entendimento sobre a composição cultural de um local.

Por este fator é importante observar as intervenções que criam novas paisagens. Numa sociedade são muitos interesses convivendo mutuamente e buscando o seu fortalecimento, procurando determinar o que mais se valoriza e, consequentemente, num jogo simbólico, aumentar a influência de determinadas ideologias.

Pensar sobre estas questões, para Hobsbawn e Ranger (1997, p.21), auxilia na compreensão das relações de poder estabelecidas num determinado espaço:

“[...] o estudo dessas tradições esclarece bastante as relações humanas com o passado e, por conseguinte, o próprio assunto e ofício do historiador. Isso porque toda a tradição inventada, na medida do possível, utiliza a história como legitimadora das ações e como cimento da coesão grupal".

Ainda é preciso destacar que registros históricos, pelo menos de modo organizado e acessível, tanto para pesquisadores como para a população de modo geral, com a devida documentação e sistematização, nem sempre estão disponíveis em seus locais de administração ou em outras fontes da cidade. Existe um vasto campo da história de Araguaína que pode ser melhor explorado e beneficiar seus habitantes e futuros estudos. 


\section{REFERÊNCIAS}

ACIARA. Associação Comercial e Industrial de Araguaína. Disponível em: http://portalaciara.com.br/aciara/. Acesso em: 18 de dez. de 2015.

ARAGUAÍNA. Turismo. Disponível em:<

http://www.araguaina.to.gov.br/portal/paginas.php?p=turismo $>$. Acesso em: 22 de dez. 2015.

CHAUI, Marilena. Manifestações ideológicas do autoritarismo brasileiro. 2. Ed. Belo Horizonte: Autêntica Editora; São Paulo: Editora Fundação Perseu Abramo, 2014.

CLAVAL, Paul. A geografia cultural. Florianópolis: Ed. da UFSC, 2007.

. (1999). O tema religião nos estudos geográficos. Revista Espaço e Cultura. n. 7. pg 37-58 jan-jun/1999 Rio de Janeiro. UERJ-NEPEC.

COSGROVE, Denis. A geografia está em toda parte: Cultura e simbolismo nas paisagens humanas. In: CORREA, Roberto Lobato \& ROZENDAHL, Zeny (orgs.). Paisagem, Tempo e Cultura. Rio de Janeiro: Eduerj, 1998.123p. p.92-123.

CRISTO REDENTOR 80 ANOS. A história. Disponível em: $<$ http://www.cristo80anos.com/historia.html $>$. Acesso em: 23 de dez. 2015. FOUCAULT, Michel. Microfisica do poder. Rio de Janeiro: Graal, $2000 .$.

G1 SÃO PAULO. Templo de Salomão é inaugurado em São Paulo. Disponível em:< http://g1.globo.com/sao-paulo/noticia/2014/07/templo-de-salomao-e-inaugurado-emsao-paulo.html<. Acesso em: 29 de dez. 2015.

GOMES, Edvânia Tôrres Aguiar. Natureza e Cultura - Representações de uma Paisagem. In: Zeny Rosendahl; Roberto Lobato Corrêa. (Org.). Paisagem, Imaginário e Espaço. Rio de Janeiro: EDUERJ, 2001.

HARDT, L. P. A. Subsídios à gestão da qualidade da paisagem urbana. 2000. $323 \mathrm{f}$. Tese (Doutorado em Engenharia Florestal) - Universidade Federal do Paraná, Curitiba, 2000.

HOBSBAWM Eric \& RANGER Terence (orgs.). A invenção das tradições. - Rio de Janeiro: Paz e Terra, 1997. $6^{\text {a }}$ ed.

IBGE. (Instituto Brasileiro de Geografia e Estatística). Histórico do município: informações complementares. Disponível em:

$<$ http://www.cidades.ibge.gov.br/xtras/perfil.php?lang=\& codmun=170210\&search=toc antins|araguaina $>$. Acesso em: 20 de dez. 2015.

LUCHIARI, Maria Tereza Duarte Paes. A (re)significação da paisagem no período contemporâneo. In: CORREAA, R. L.; ROSENDAHL, Z. (orgs.). Paisagem, imaginário e espaço. Rio de Janeiro: Eduerj, 2001. p. 9-28.

LYNCH, K. A imagem da cidade. Edições 70, Lisboa, 1999.. 
MANNHEIM, Karl. Ideologia e Utopia. Rio de Janeiro: Zahar Editores, 1976.

MAXIMIANO, Liz Abad. Considerações sobre o conceito de paisagem. In:

R.RA'ECA. Curitiba: UFPR, 2004. n 8, p. 83-91.

MELO, Vera Mayrinck. Paisagem e simbolismo. In: CORRÊA, Roberto Lobato; ROSENDAHL, Zeny (Orgs.). Paisagem, imaginário e espaço. Rio de Janeiro: EdUERJ, 2001 .

RICOUER, Paul. Interpretação e ideologias; organização, tradução e apresentação Hilton Jaipiassu. Rio de Janeiro, F. Alves, 1990.

ROSENDAHL, Zeny. Espaço, cultura e religião. In: Introdução à geografia cultural. Rios de Janeiro: Bertrand Brasil, 2007.

SANTOS, Milton. Metamorfose do espaço habitado. São Paulo: EDUSP, 2008.

SCHAMA, Simon. Paisagem e memória. São Paulo: Companhia das letras, 1996.

SIMMEL, Georg. A filosofia da paisagem. Tradução de Artur Morão. Covilha, 2009. 18 p. Disponível em:

HTTP://www.lusofia.net/textos/simmel_georg_filosofia_da_paisagem.pdf. Acesso em 04 set. 2015.

PARÓQUIA SAGRADO CORAÇÃO DE JESUS. A paróquia. Disponível em:< http://paroquiasagradocoracaodejesus.net/?page_id=635>. Acesso em: 15 de dez. 2015.

RAMOS, Beatriz Guida. Entrevista sobre a Paróquia São José Operário. Araguaína, Secretaria da Paróquia São José Operário, 14/01/2016. Entrevista Marcelo Trilha Muniz.

SOARES, Mária do rosário. Entrevista sobre o monumento Orionita Nossa Senhora da Rosa Mística. Araguaína, Secretaria da Paróquia Sagrado Coração de Jesus, 11/01/2016. Entrevista Susie Fernandes.

THOMPSON, John. Ideologia e cultura moderna: teoria social crítica da era dos meios de comunicação. 9 ed. Petrópolis: Vozes, 2011.

TUAN, Yi-Fu. Espaço e lugar: a perspectiva da experiência. Trad. Lívia Oliveira. Londrina: Eduel, 2013.

TUPINIQUIM, Luiz. Entrevista sobre Estátua do Cristo Redentor de Araguaína. Araguaína, Prefeitura Municipal, 10/01/2016. Entrevista Susie Fernandes.

WAGNER, Philip; MIKESELL, Marvin. Os Temas da Geografia Cultural. In: CORRÊA, Roberto Lobato; ROSENDAHL, Zeny (Org.). Introdução à Geografia Cultural. 2. ed. Rio de Janeiro: Bertrand Brasil, 2007. p. 27-62. 